\title{
A novel mode of chromosomal evolution peculiar to filamentous Ascomycete fungi
}

James K Hane ${ }^{1,2}$, Thierry Rouxel ${ }^{3}$, Barbara J Howlett ${ }^{4}$, Gert HJ Kema ${ }^{5}$, Stephen B Goodwin ${ }^{6}$ and Richard P Oliver ${ }^{7 *}$

\begin{abstract}
Background: Gene loss, inversions, translocations, and other chromosomal rearrangements vary among species, resulting in different rates of structural genome evolution. Major chromosomal rearrangements are rare in most eukaryotes, giving large regions with the same genes in the same order and orientation across species. These regions of macrosynteny have been very useful for locating homologous genes in different species and to guide the assembly of genome sequences. Previous analyses in the fungi have indicated that macrosynteny is rare; instead, comparisons across species show no synteny or only microsyntenic regions encompassing usually five or fewer genes. To test the hypothesis that chromosomal evolution is different in the fungi compared to other eukaryotes, synteny was compared between species of the major fungal taxa.

Results: These analyses identified a novel form of evolution in which genes are conserved within homologous chromosomes, but with randomized orders and orientations. This mode of evolution is designated mesosynteny, to differentiate it from micro- and macrosynteny seen in other organisms. Mesosynteny is an alternative evolutionary pathway very different from macrosyntenic conservation. Surprisingly, mesosynteny was not found in all fungal groups. Instead, mesosynteny appears to be restricted to filamentous Ascomycetes and was most striking between species in the Dothideomycetes.

Conclusions: The existence of mesosynteny between relatively distantly related Ascomycetes could be explained by a high frequency of chromosomal inversions, but translocations must be extremely rare. The mechanism for this phenomenon is not known, but presumably involves generation of frequent inversions during meiosis.
\end{abstract}

\section{Background}

The evolutionary history of organisms, as revealed by comparisons of genome sequences, is of the greatest biological significance and interest. The current explosion in the number of genome assemblies of species within the same class, order and genus is allowing the whole-genome interrelationships between organisms to be examined in ever greater detail. There is a long history of comparisons of individual orthologous gene sequences and these have revolutionized our understanding of phylogenetic relationships [1]. A more complete understanding of both the mechanism and results of evolution can be obtained by comparing entire genomes [2]. These comparisons have refined the concept of synteny. This term is used loosely by

\footnotetext{
* Correspondence: richard.oliver@curtin.edu.au

${ }^{7}$ Australian Centre for Necrotrophic Fungal Pathogens, Curtin University, Perth, 6845, Australia Full list of author information is available at the end of the article
}

many authors. Originally it was used in cytogenetics to describe two or more loci that are located on the same chromosome. As DNA sequencing and comparative genomics became commonplace, the term synteny acquired the additional property of co-linearity; i.e. the conservation of gene order and orientation. In this study we refer to synteny in the original cytogenetic sense and describe co-linearity as a sub-category of synteny. If orthologs of multiple genes that are colocated in the genome of one organism are co-located in another species, the chromosomes on which the genes reside are said to be syntenic. Synteny can also be quantitative; chromosomes that contain all of the same genes are $100 \%$ syntenic.

The process of speciation occurs when two independent populations diverge into reproductively isolated species. Initially the daughter species would have had chromosomes that shared both gene content (synteny) and order (co-linearity). Over evolutionary time, the
C Biomed Central 
degree of synteny and co-linearity would be degraded through various processes, including chromosomal duplications, gene losses/gains and chromosomal rearrangements (Additional file 1), until orthologous genes in one species occur randomly in the genome of the other.

The related concepts of synteny and co-linearity have been refined mostly in plants, animals and bacteria. Synteny has been differentiated qualitatively based on the length and completeness of co-linear regions. Macrosynteny describes co-linearity observable at a whole-chromosome scale, involving hundreds or thousands of genes of which a backbone are co-linear. Microsynteny describes co-linearity spanning a small number (for example, two to ten) of successive genes. Comparisons of vertebrate and flowering plant species within taxonomic families often have shown extensive macrosynteny [3-8]. Macrosynteny has been exploited to assist genetic mapping and gene cloning; examples include the use of the Arabidopsis genome to find genes in canola [9], and rice/Brachypodium synteny to locate genes in wheat and barley [10].
Filamentous fungi form an ancient, large and diverse group of organisms. Until the last decade, the phylogenetics of fungi was problematic but the application of techniques based on gene sequence variation has created a stable taxonomy. The ascomycete filamentous fungi are mostly within the sub-phylum Pezizomycotina (Figure 1) [11]. This sub-phylum contains four major classes: Dothideomycetes, Eurotiomycetes, Sordariomycetes and Leotiomycetes. The Dothideomycetes contains more than 20,000 species amongst which are many of the most important plant pathogens worldwide, including those in the genera Phaeosphaeria, Leptosphaeria and Mycosphaerella.

Evolutionary diversity within the filamentous ascomycete fungi is much higher than in flowering plants or vertebrate animals [12]. A number of reasons have been proposed to account for this. Filamentous fungi reflect approximately 400 million years of evolutionary history, comparable to that of the vertebrates but approximately four times longer than that of the flowering plants [13] (Figure 1; Table 1). The generation times of fungi are typically measured in hours or days, whereas plants and

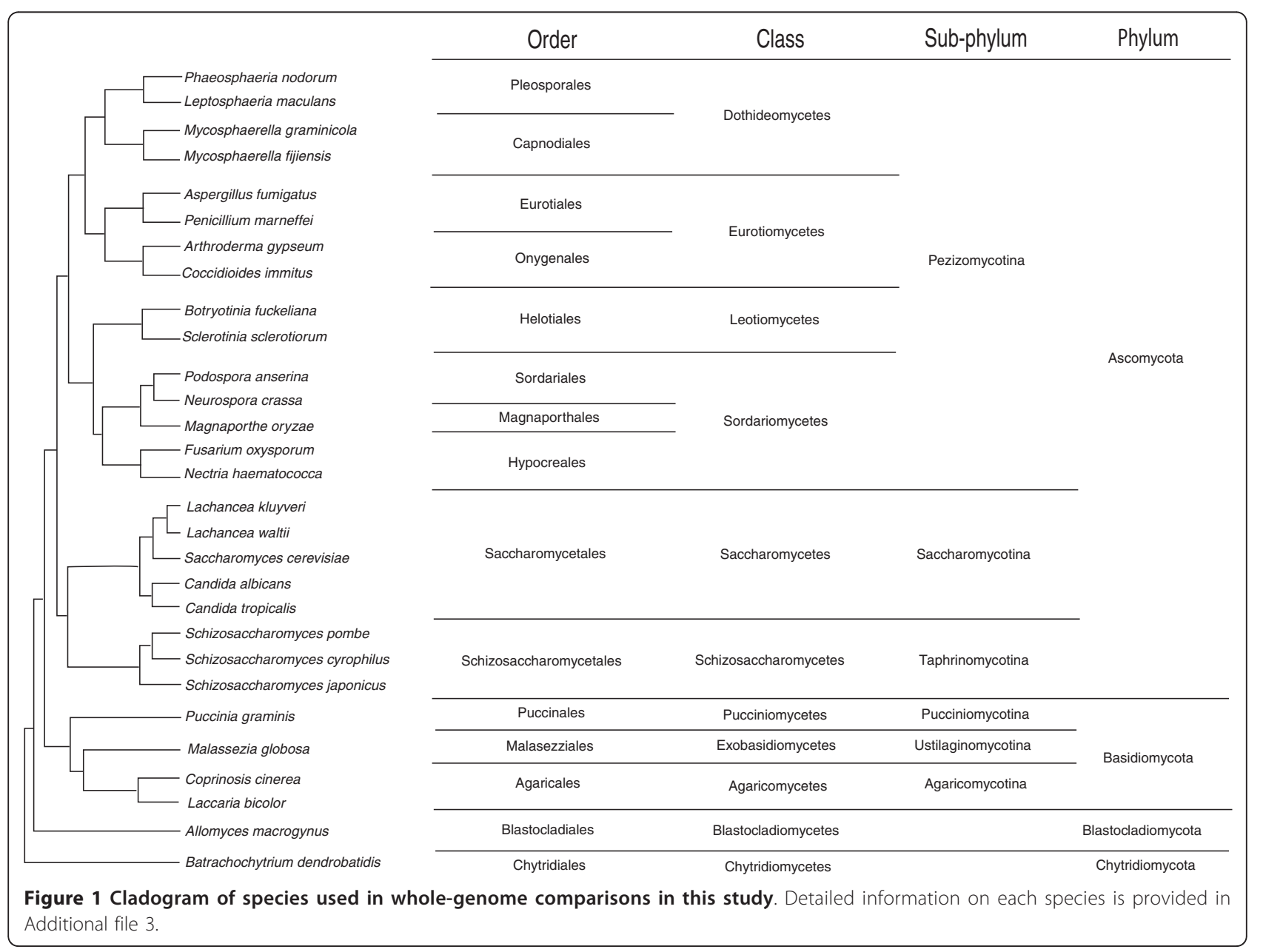


Table 1 Summary of whole-genome synteny relationships across selected fungal orders

\begin{tabular}{|c|c|c|c|c|c|c|c|c|c|c|c|}
\hline \multirow[b]{3}{*}{ Class } & \multirow{3}{*}{$\begin{array}{l}\text { Sub-phylum } \\
\text { Class } \\
\text { Order }\end{array}$} & \multicolumn{8}{|c|}{ Pezizomycotina } & \multirow{3}{*}{$\begin{array}{c}\text { Saccharomycotina } \\
\text { Saccharomycetes } \\
\text { Saccharomycetales }\end{array}$} & \multirow{3}{*}{$\begin{array}{c}\text { Taphrinomycotina } \\
\text { Schizosaccharomycetes } \\
\text { Schizosaccharomycetales }\end{array}$} \\
\hline & & \multicolumn{2}{|c|}{ Dothideomycetes } & \multicolumn{2}{|c|}{ Eurotiomycetes } & \multicolumn{3}{|c|}{ Sordariomycetes } & \multirow{2}{*}{$\begin{array}{c}\text { Leotiomycetes } \\
\text { Helotiales }\end{array}$} & & \\
\hline & & Capnodiales & Pleosporales & Eurotiales & Onygenales & Hypocreales & Magnaporthales & Sordariales & & & \\
\hline \multirow[t]{2}{*}{ Dothideomycetes } & Capnodiales & Meso/150 & Meso & Demeso & Demeso & Demeso & None & Demeso & Demeso & None & None \\
\hline & Pleosporales & 300 & Meso/120 & Demeso & Demeso & Demeso & None & Demeso & Demeso & None & None \\
\hline \multirow[t]{2}{*}{ Eurotiomycetes } & Eurotiales & 370 & 370 & $\begin{array}{c}\text { Demacro/< } \\
160\end{array}$ & Demacro & None & None & None & Demeso & None & None \\
\hline & Onygenales & 370 & 370 & 150 & $\begin{array}{c}\text { Demacro/< } \\
160\end{array}$ & None & None & None & Demeso & None & None \\
\hline \multirow[t]{3}{*}{ Sordariomycetes } & Hypocreales & 370 & 370 & 370 & 370 & Macro/170 & Demeso & Demeso & Demeso & None & None \\
\hline & Magnaporthales & 370 & 370 & 370 & 370 & 240 & NA & Demeso & Demeso & None & None \\
\hline & Sordariales & 370 & 370 & 370 & 370 & 225 & 240 & Demeso & Demeso & None & None \\
\hline Leotiomycetes & Helotiales & 370 & 370 & 370 & 370 & 340 & 340 & 340 & Macro/250 & None & None \\
\hline \multirow[t]{2}{*}{ Saccharomycetes } & Saccharomycetales & 500 & 500 & 500 & 500 & 500 & 500 & 500 & 500 & Demacro/none/250 & None \\
\hline & Schizosaccharomycetales & 650 & 650 & 650 & 650 & 650 & 650 & 650 & 650 & 650 & Demacro/none/240 \\
\hline
\end{tabular}

Whole-genome synteny, indicated above the diagonal, was classified as either macrosynteny (macro), degraded macrosynteny (demacro), mesosynteny (meso), degraded mesosynteny (demeso) or no synteny (none). 'NA' indicates lack of sufficient data to perform whole-genome comparisons. Time since divergence between orders, previously predicted within the Ascomycetes [38], is indicated below the diagonal in millions of years. 
animals have generation times of many weeks, years or even decades. Meiosis is a powerful force stabilising chromosomal structure and may occur less commonly in some fungi compared to plants and animals; whilst nearly all filamentous fungi undergo germline asexual reproduction, only a subset have known sexual phases. Furthermore, many filamentous fungi can acquire genetic material by lateral gene transfer, which can increase their rate of evolution [14-16]. All of these factors would tend to reduce or eliminate the extent of synteny between species. It was not surprising, therefore, when initial comparisons between fungal genome sequences failed to find extensive evidence of interspecific macro- or microsynteny [17-22] and, with the exception of the aspergilli, even between species from the same genus [23-25].

The number of sequenced fungal genomes has increased dramatically since 2008. There is now a sufficient number of sequenced species within each fungal class to begin to assess whole-genome patterns of evolution. In this paper, we have applied a simple dot-plot approach to fungal genome comparisons and observed a striking pattern of chromosome-level evolutionary conservation. This pattern is characterized by the conservation of gene content in chromosomes, without conservation of gene order or orientation; that is, synteny without co-linearity. We propose to call this sequence conservation 'mesosynteny' to distinguish it from micro- and macrosynteny. Mesosynteny appears to be peculiar to the filamentous Ascomycetes (syn. Pezizomycotina), particularly in the class Dothideomycetes. This phenomenon has interesting implications for the study of genome evolution and may have applications in the sequencing and assembly of fungal genomes.

\section{Results}

Dot plots are a well-established method of representing sequence comparisons [26]. Comparison of co-linear genomes (Supplementary Figure S1a in Additional file 1) gives a series of dots that lie on the diagonal (Supplementary Figure S1b in Additional file 1). Random gene loss from either chromosome without major rearrangements (Supplementary Figure S1c, d in Additional file 1) progressively destroys microsynteny but retains macrosynteny. Inversions are visualised on dot plots by diagonal lines with the opposite slope, while translocations are indicated when the genes on a chromosome of one species share syntenic blocks with two or more chromosomes. Conservation of short, contiguous runs of genes, whether on the same or different chromosomes, retains microsynteny but not macrosynteny.

The fungus Phaeosphaeria (syn. Stagonospora, Septoria) nodorum is a major pathogen of wheat [27]. It is a member of the class Dothideomycetes (Figure 1), a taxon that includes more than 20,000 species amongst which are many dominant crop pathogens [28]. Its genome, which is believed to comprise 14 to 19 chromosomes [29], was assembled as 107 nuclear scaffolds [21]. Expressed sequence tag and proteomic data have refined the annotations to a set of 12,194 genes [30-32]. Pathogenicity in P. nodorum has been linked to the expression of a suite of necrotrophic effectors [33-36] (formerly called host-specific toxins), some of which appear to have been acquired by lateral gene transfer $[14,16]$.

The genome sequences of other Dothideomycetes species have become available recently, allowing whole-genome comparisons with relatively closely related taxa. We used the software tool MUMmer [37] to generate dot plots that compare the scaffolds of the $P$. nodorum assembly with the 21 finished chromosomes of Mycosphaerella graminicola $[38,39]$ (Figure 2a). These species are classified respectively in the Pleosporales and the Capnodiales, order-level taxa within the Dothideomycetes (Figure 2), with an estimated divergence time of (very approximately) 300 million years ago (Mya). The figure is arranged with the chromosomes or scaffolds of each species arranged in size order along the axes. Dots correspond to regions of sequence similarity and are color-coded to indicate their degree of identity.

Our expectation was that we would see either dispersed diagonal lines or a completely random distribution of very short matches ('dots'). Instead, the dot plot shows a highly non-random distribution whereby dots from individual chromosomes of $M$. graminicola appear to be strongly associated with one or a few scaffolds of $P$. nodorum, indicated by 'boxes' within columns and rows. For example, dots corresponding to $P$. nodorum scaffold 7 were almost exclusively found within the box corresponding to M. graminicola chromosome 12. Reciprocally, dots corresponding to M. graminicola chromosome 12 appeared predominantly within the box corresponding to $P$. nodorum scaffold 7 . The dots within this box did not fall on any obvious diagonal lines and were instead arranged quasi-randomly. When these two sequences were aligned (Figure $2 b$ ), lines joining regions of significant similarity were distributed quasi-randomly. The orientation of the genes (color coded as red for parallel and blue for inverted) also appeared to be random. The dot plots used six-frame back translations of the genomes. Similar results were obtained with raw nucleotide sequences or when validated genes were used (Additional file 2). This indicated that the majority of the dots corresponded to genes.

We call this pattern of dots-within-boxes 'mesosynteny'. The non-random distribution implies conservation of the gene content of scaffolds (and by implication, chromosomes) during evolution; hence, this is a form of 
(a)

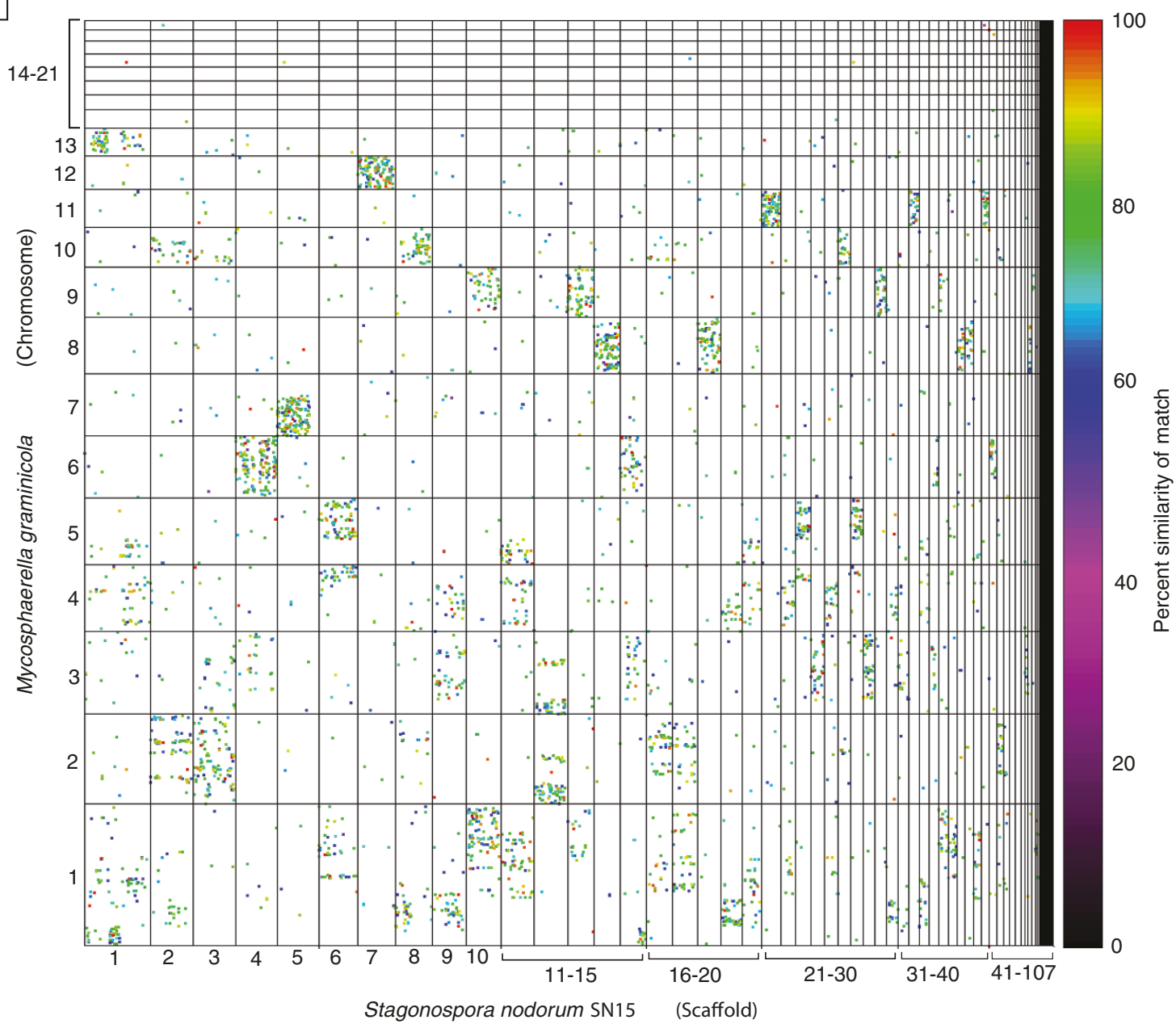

(b)

\section{Mycosphaerella graminicola Chromosome 12}

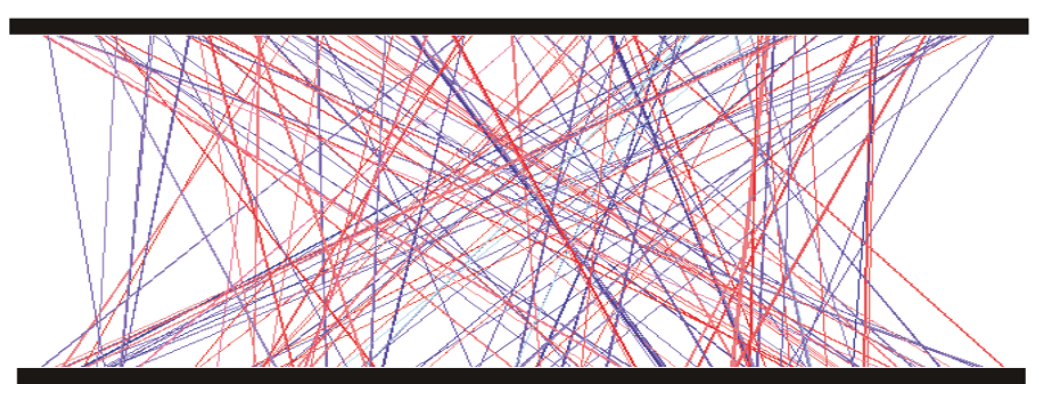

Stagonospora nodorum SN15 Scaffold 7

Figure 2 Whole-genome dot-plot comparison between the Dothideomycetes species Mycosphaerella graminicola and Phaeosphaeria nodorum. (a) The six-frame translations of both genomes were compared via MUMmer 3.0. Homologous regions are plotted as dots, which are color coded for percent similarity as per the color bar (right). Chromosomes 1 to 21 from M. graminicola are displayed by decreasing size along the $y$ axis and scaffolds 1 to 107 from $P$. nodorum are displayed along the $x$ axis. Dots represent matching regions between translated scaffold sequences. Mesosyntenic regions appear as dots within boxes without any obvious diagonal lines. (b) Homology relationships between chromosome 12 of M. graminicola and scaffold 17 of P. nodorum. Red lines link parallel homologous pairs and blue lines link anti-parallel pairs. 
synteny [40] that does not involve the retention of colinearity as found in both macro- and microsynteny.

\section{Taxonomic distribution of mesosynteny across the fungal} kingdom

To test the extent and generality of mesosynteny within the fungi, the analysis was extended to other species within the Dothideomycetes, other classes within the Pezizomycotina and other fungal phyla. These comparisons were tested for chromosomal-scale genome conservation and were classified as macrosyntenic, mesosyntenic, or non-syntenic (Figure 3; Additional file 3).

Visual inspection of dot plots distinguished the comparisons neatly into three classes: no synteny,

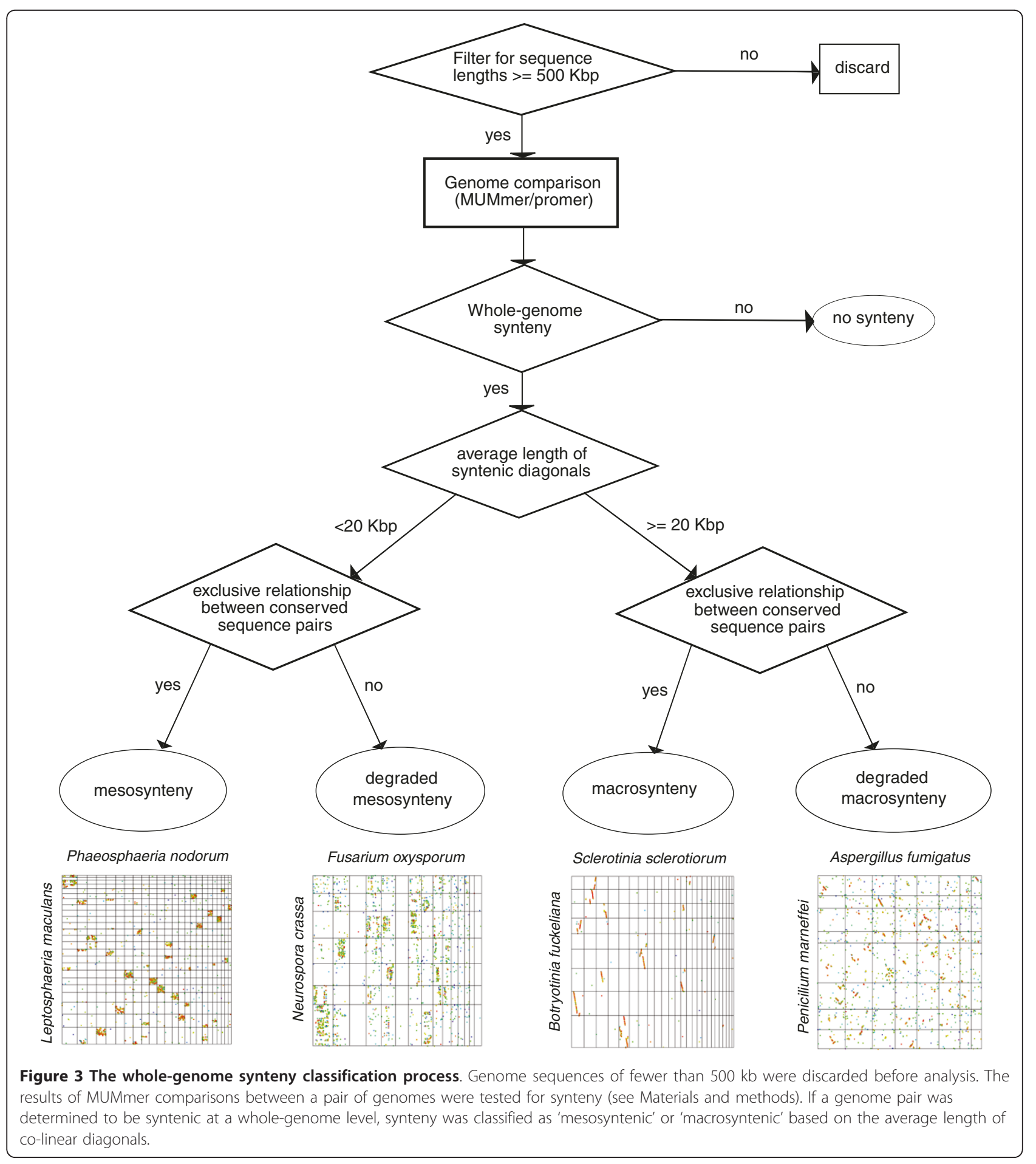


macrosynteny or mesosynteny. Quantifying the degree of synteny between species required the development of new statistical tests. Significant sequence conservation was tested between pairs of scaffolds by a one-tailed cumulative binomial test, requiring a probability of $\geq 0.99$. The whole-genome conservation was defined as significant when $\geq 25 \%$ of the expected number of scaffold pairs (assuming perfect whole-genome synteny) were conserved. Species pairs showing synteny were classified as macro- or mesosynteny based on the average length of co-linear runs of sequence matches between both genomes; an average co-linear diagonal length of $\geq 20 \mathrm{~kb}$ was considered macrosyteny and $<20$ kb was classified as mesosynteny (Additional file 3). Mesosynteny and macrosynteny were further categorized into 'degraded' or 'non-degraded' (Figure 3). Synteny was classified as degraded when significant clusters of 'dots' or 'lines' were found outside of the primary box (that is, for any given 'box', $<75 \%$ of the total length of conserved sequences within its corresponding rows and columns resided within the dominant box). Scaffolds shorter than $500 \mathrm{~kb}$ were excluded from these analyses.

Dot-plot comparisons between the Dothideomycetes species $P$. nodorum, M. graminicola, Mycosphaerella fijiensis and Leptosphaeria maculans showed significant mesosynteny (Figure 4). The comparison between $P$. nodorum and L. maculans (both in the order Pleosporales) was especially striking (Additional file 2). The dot plot was dominated by matches of 80 to $100 \%$ similarity, compared to 60 to $80 \%$ in the case of $P$. nodorum versus the species in the Capnodiales, M. graminicola or $M$. fijiensis. The dots in the comparison between $P$. nodorum and L. maculans were almost exclusively restricted to single boxes within both rows and columns. As before, there was no indication of the diagonal lines characteristic of macrosynteny. This pattern of nearly exclusive dots within single boxes was also observed when comparisons were made between these genomes and the other released but so far unpublished Dothideomycetes genomes available via the JGI and Broad Institute web sites $([39,41,42]$ and data not shown).

Dothideomycetes species also showed a discernable level of mesosynteny-like conservation with species representing the classes Eurotiomycetes (Aspergillus fumigatus), and the Leotiomycetes (Sclerotinia sclerotiorum; S. sclerotiorum sequencing project [43]), but not with the Sordariomycetes (Magnaporthe oryzae) or the Saccharomycetes (Saccharomyces cerevisiae) (Figure 4; Additional file 1). Comparisons of $P$. nodorum and $M$. graminicola with A. fumigatus and S. sclerotiorum had a statistically significant non-random distribution of dots within boxes. In contrast to intra-Dothideomycetes comparisons, dots appeared in multiple boxes within a row and column. This is an example of degraded mesosynteny. Comparisons between Dothideomycetes and $M$. oryzae (Sordariomycetes) and the yeast S. cerevisiae (Saccharomycetes) failed to find a statistically significant degree of synteny, reflected in the apparently random distribution of dots. These comparisons had an average of 1 and 0 sequences with binomial probabilities of significant sequence conservation $>0.99$. No statistically significant syntenic relationships were found when either $M$. oryzae or any yeast was compared with other filamentous fungal genomes.

A similar series of dot-plot comparisons between the class Eurotiomycetes and Leotiomycetes and species from classes of the Ascomycota is shown in Figure 5. The test species are A. fumigatus and S. sclerotiorum. The comparisons between S. sclerotiorum and Botryotinia fuckeliana exhibited a highly conserved pattern with many obvious diagonal lines made up of red and yellow dots representing highly similar (90 to 100\%) sequence pairs. The average length of co-linear regions was much greater than $20 \mathrm{~kb}$. This is a classical macrosyntenic pattern reflecting very recent divergence between these closely related genera. A weaker macrosyntenic pattern was observed between A. fumigatus and Penicillium marnef$f e i$, two species in the Eurotiales. Less than $25 \%$ of matches in columns and rows resided within a single box, characteristic of degraded macrosynteny. Comparisons between A. fumigatus and S. sclerotiorum and the Dothideomycetes, represented by L. maculans, revealed degraded mesosynteny. This was also observed between $S$. sclerotiorum and the two members of the Eurotiales, A. fumigatus and P. marneffei.

The Sordariomycetes Fusarium oxysporum exhibited mixed patterns of synteny in comparisons between species from the related orders Sordariales and Hypocreales and from other classes in the Pezizomycotina (Figure 6; Additional file 4). Striking macrosynteny was observed between chromosomes 1, 2, 4, 5 and 7 to 10 of F. oxysporum and chromosomes 1 to 6 and 7 to 10 of Nectria haematococca. Parts of chromosomes 3, 6 and 11 to 14 of $F$. oxysporum exhibited a mesosyntenic pattern with chromosomes 7 and 11 to 14 of $N$. haematococca. Mesosynteny was strongest between $N$. haematococca chromosome 14 and parts of $F$. oxysporum chromosomes 3, 6, 14 and 15. Degraded mesosynteny was observed between F. oxysporum and Neurospora crassa, S. sclerotiorum, A. fumigatus and with P. nodorum. However, in all comparisons (excluding $N$. haematococca), dots were conspicuously absent from rows corresponding to F. oxysporum chromosomes 3, 6, 14 and 15 (Figure 6).

The comparison between $N$. crassa and Podospora anserina (order Sordariales) showed a dominant pattern of mesosynteny, with some macrosyntenic regions particularly between the largest chromosome of both species 


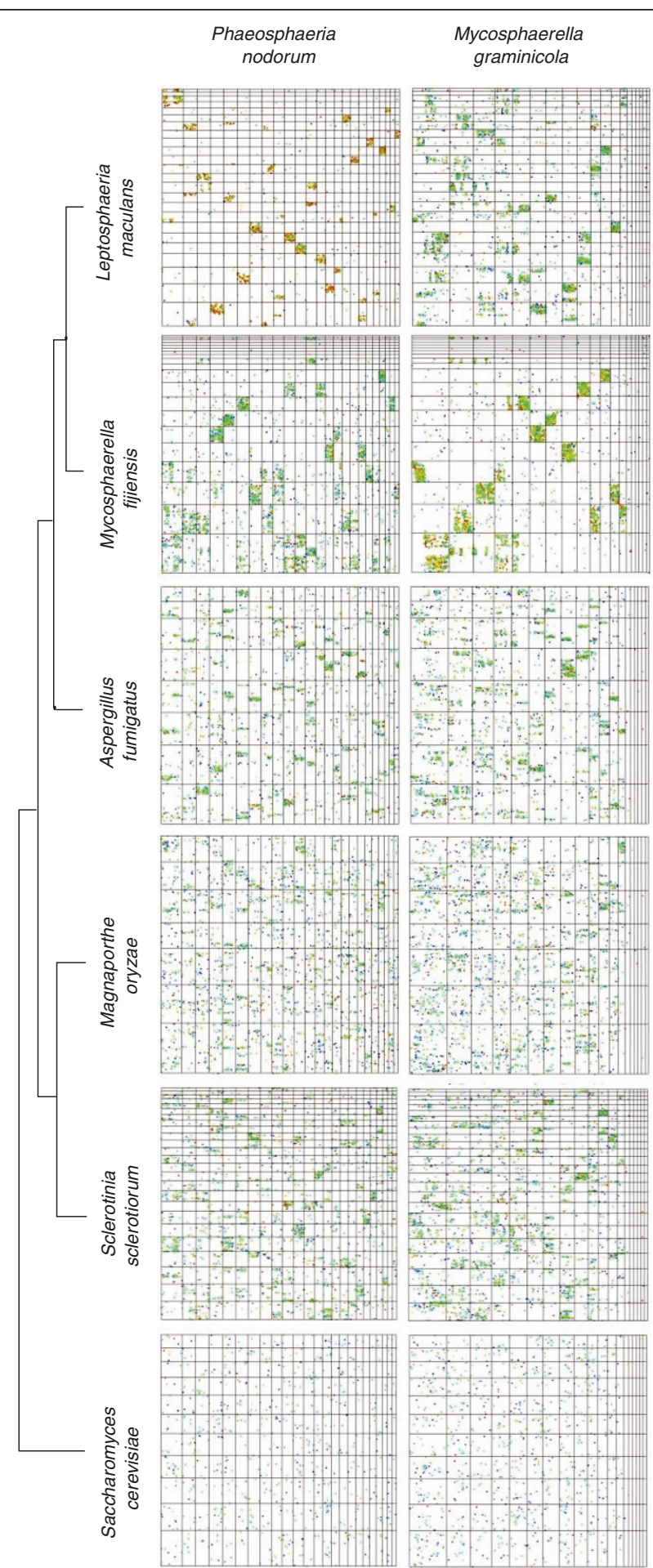

Figure 4 Dot-plot comparisons between the class Dothideomycetes and related classes. Scaffolds greater than $500 \mathrm{~kb}$ in length are ordered in ascending alpha-numeric order upwards along the $y$-axis and left-to-right along the $x$-axis. The orders Pleosporales (represented by $P$. nodorum and L. maculans) and Capnodiales (Mycosphaerella spp.) of the Dothideomycetes exhibit a tightly clustered pattern of mesosynteny between and within each order. This degrades into a mesosynteny-like pattern in comparisons between Dothideomycetes and the classes Eurotiomycetes (A. fumigatus), Sordariomycetes (M. oryzae) and Leotiomycetes (S. sclerotiorum). Clustered blocks can still be observed in these comparisons. The dot-plots comparing Dothideomycetes and Saccharomycetes (S. cerevisiae) appear to be random - that is, there was no synteny. 

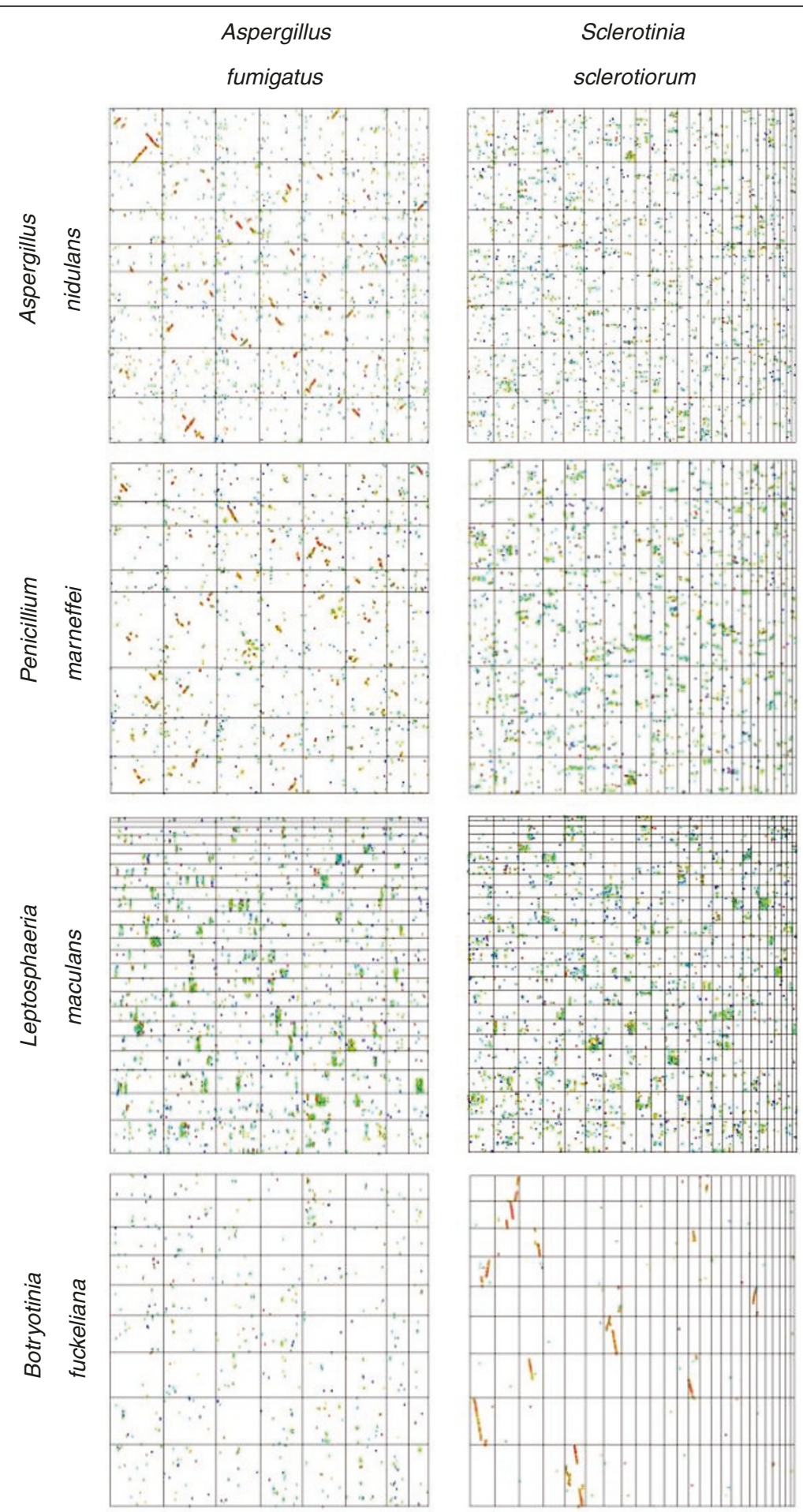

Figure 5 Dot-plot comparisons between representatives of the classes Eurotiomycetes and Leotiomycetes and related classes. The orders Eurotiales (Aspergillus spp.) and Onygenales (P. marneffei) of the Eurotiomycetes exhibit degraded macrosynteny between and within each order. The Leotiomycetes exhibit macrosynteny between species of the order Helotiales. A mesosynteny-like pattern is observed in comparisons between the Eurotiomycetes, Leotiomycetes and the more distantly related class Dothideomycetes (L. maculans). 


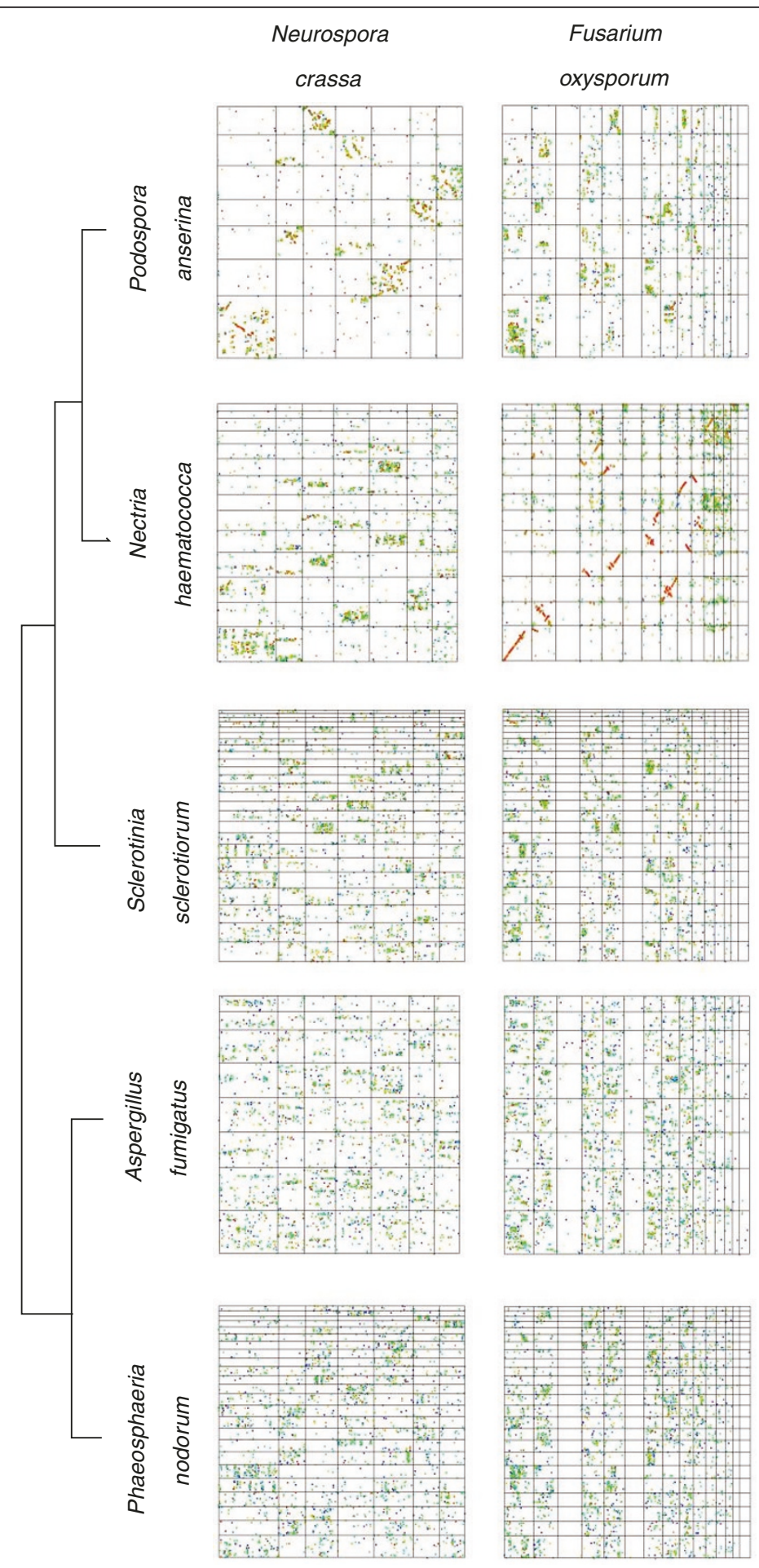

Figure 6 Dot-plot comparisons between two members of the class Sordariomycetes and related classes. The orders Sordariales ( $N$. crassa and $P$. anserina) and Hypocreales (F. oxysporum and N. haematococca) of the Sordariomycetes generally exhibit mesosynteny-like conservation. The closely related pair of Hypocreales species Fusarium oxysporum and Nectria haematococca exhibit mostly macrosynteny with mesosynteny between a few chromosomes. Comparisons between the Sordariales and Hypocreales with the classes Leotiomycetes, Eurotiomycetes and Dothideomycetes exhibit degraded mesosynteny. Lack of synteny between the conditionally dispensable chromosomes 3, 6, 14 and 15 of $F$. oxysporum (excluding $N$. haematococca) with chromosomes of any other species is evident by an absence of dots in those comparisons. 
[20]. N. crassa exhibited degraded mesosynteny when compared to $S$. sclerotiorum, A. fumigatus and $P$. nodorum (Figure 6).

We expanded these comparisons beyond the classes presented above to include additional species of the subphyla Saccharomycotina and Taphrinomycotina within the phylum Ascomycota and species from the phyla Basidiomycota, Blastocladiomycota and Chytridiomycota (Table 1; Figure 1). Non-filamentous Ascomycetes (classes Saccharomycetes and Schizosaccharomycetes) exhibited either macrosynteny or no synteny within their respective classes and no synteny with other fungal classes (Additional file 5). The class Agaricomycetes exhibited degraded macrosynteny between species within the class and no synteny with other fungal classes (Additional file 6). No non-Pezizomycotina taxa showed any level of synteny when compared to species of a different class (Table 1; Additional file 1).

\section{Discussion}

A novel and unexpected mode of chromosome-level sequence conservation, which we have called mesosynteny, has been detected between species of filamentous Ascomycetes, and in particular the Dothideomycetes. Mesosynteny implies the conservation of gene content within chromosomes but without conservation of gene order or orientation. It contrasts markedly with the macrosynteny observed commonly in plants and animals and the absence of synteny seen in other eukaryotes such as distantly related yeast species. The cause of mesosyntenic chromosomal evolution is not known. However, a mesosyntenic pattern would be expected to occur if intra-chromosomal recombination (including inversions) occurred significantly more frequently than inter-chromosomal recombinational events such as translocations.

Mesosynteny is distinct from macrosynteny. Macrosynteny would be expected to arise when the predominant modes of chromosomal evolution are interchromosomal recombination and gene loss. These considerations suggest that different patterns of mutagenic events can lead either to mesosynteny or to macrosynteny as chromosomes evolve following a speciation event.

Mesosynteny also is distinct from microsynteny, which is characterized by co-linearity between clusters of two to about ten genes with both order and orientation conserved. Earlier comparisons of synteny in related filamentous fungi frequently found clusters of genes with related functions but without retention of gene order or orientation. An example is the quinate cluster, which is conserved across species of the Ascomycetes [21,44]. This pattern of shuffled cluster retention is akin to what we observe at the whole-chromosome level.
Our results suggest that mesosyntenic chromosomal conservation is restricted to the Pezizomycotina and is most pronounced in the Dothideomycetes [45]. The Dothideomycetes are the only group to exhibit nondegraded mesosynteny between species of the different genera (estimated to have diverged approximately 120 to $150 \mathrm{Mya}$ ) and orders (approximately $300 \mathrm{Mya}$ ). A recognizable yet degraded form of mesosynteny was found between many species of Pezizomycotina outside the Dothideomycetes. The estimated time of divergence within Dothideomycetes orders are comparable to other orders within the Pezizomycotina that exhibited either degraded mesosynteny or no detectable synteny (Table 1) [38]. No mesosynteny was observed in any of the fungal groups outside of the Pezizomycotina that were surveyed: yeasts, Basidiomycetes, Blastocladiomycetes and Chytridiomycetes. The evolutionary separation between these groups and the Dothideomycetes (500 to 650 Mya) [38] may be so great that both mesosynteny and macrosynteny have decayed below the limit of detection. To our knowledge, mesosynteny has not been observed in non-fungal eukaryotes. Superficially similar dot-plots have been occasionally observed in comparisons of chordate genomes [45] but appear to be due to the amplification of paralogous copies of genes within chromosomes. Overall, either macrosynteny or no synteny has been found outside the Pezizomycotina.

Chromosomal conservation akin to mesosynteny had been observed previously in a number of inter-species comparisons within the Pezizomycotina, but its full extent was not analyzed. These include comparisons between the Pezizomycetes Tuber melanosporum and the Eurotiomycetes Coccidioides immitus [46] and the Sordariomycetes $P$. anserina and $N$. crassa [20]. As $N$. crassa and $P$. anserina are heterothallic, the authors suggested that the observed conservation may be specific to out-crossing (heterothallic) fungi. However, evidence from this study suggests otherwise as mesosynteny was observed between both heterothallic and homothallic species (Table 1; Additional files 3 and 5). For example, two homothallic Sordariomycetes species, which diverged approximately 225 Mya [38], exhibited degraded mesosynteny (Fusarium graminearum and Chaetomium globosum; Additional file 7).

Mesosynteny was observed in species both with and without (F. oxysporum [47] and Penicillium marneffei [48]) a known sexual stage. It may be that sexual crossing has been lost relatively recently in these species. Nonetheless, this finding suggests that mesosyntenic relationships were not quickly lost in the absence of meiosis. Amongst the mesosyntenic Pezizomycotina, mesosynteny was weakest in comparisons against the $M$. oryzae genome (Figures 5 and 6; Table 1). M. oryzae is 
believed to exist in nature in purely asexual lineages. The sequenced isolate of $M$. oryzae was a fertile derivative of two asexual lineages [19]. We speculate that a history of asexual reproduction and/or the process of laboratory domestication may have destroyed the remnants of mesosynteny in this isolate. This hypothesis could be tested by comparisons with genome sequences from additional isolates of $M$. oryzae or related species in the Magnaporthales.

In some species there was an uneven distribution of syntenic relationships between different chromosomes. The genome of M. graminicola has been finished [39] and comprises 21 chromosomes, the eight smallest of which have been shown to be dispensable [49]. These dispensable chromosomes displayed little sequence conservation with genes from any other species, and therefore no detectable synteny of any type (Figure 4). In contrast, the M. graminicola core chromosomes exhibited a typical mesosyntenic pattern in most comparisons with other Pezizomycotina species. Similarly, the conditionally dispensable chromosomes (CDCs) of F. oxysporum (3, 6, 14 and 15) showed no synteny with almost all species tested. All of these supernumerary chromosomes are thought to have originated by lateral transfer from unknown donor species [39,50]. Whether the lack of synteny of most supernumerary chromosomes is because they come from distantly related species or because they evolve more rapidly than core chromosomes is not known.

Surprisingly, CDC 14 of $N$. haematococca was mesosyntenic to $F$. oxysporum CDCs (chromosome 14 and the terminal end of chromosomes 3 and 6; Figure 6; Additional file 4). This is in contrast to the core chromosomes of each species, which exhibited macrosynteny and to previous comparisons that had indicated that these CDCs were non-syntenic. A comparison of the $F$. oxysporum genome with the closely related Fusarium verticillioides indicated that the $F$. oxysporum $C D C s$ were not syntenic [50]. A possible explanation for this phenomenon is that mutations and rearrangements in supernumerary chromosomes accumulate more rapidly because these chromosomes are rarely required for survival. Faster accumulation of mutations potentially coupled with origins in distantly related donor species may allow the sequences of supernumerary chromosomes to diverge to the point where no sequence similarity remains (as in M. graminicola). The occurrence of mesosyntenic rearrangement in F. oxysporum and $N$. haematococca may also be related to the origin of their CDCs. These may have arisen in their common ancestor from a single chromosome, which subsequently mutated and broke into smaller chromosomes. Alternatively, they may have been recently transferred laterally from a common (or closely related) donor.
Whole-genome shotgun sequencing involves the generation of many short DNA reads that are assembled into longer segments. Macrosyntenic relationships are commonly used to assist the assembly and finishing of fragmented genome sequences, particularly in prokaryotic genomes. Sequences that are macrosyntenic to a long sequence of a closely related genome can be confidently hypothesized to be joined physically. Mesosynteny between a new genome assembly with a reference genome also may be used to suggest which scaffolds are juxtaposed. This could significantly reduce the cost and complexity of assembling and finishing genomes. To test whether mesosynteny could be used to predict scaffold joins in genomic sequences, early and late assemblies of the $M$. graminicola genome were analyzed to determine whether the joining of contigs or scaffolds in the finished genome could have been predicted by mesosyntenic relationships of the draft genome to $P$. nodorum [39]. Mesosynteny was remarkably successful in predicting separate scaffolds that should be joined and for identifying mis-joins in the initial assembly. This approach has the potential to assist with assembly and finishing of other genomes within the Pezizomycotina.

\section{Conclusions}

We have unearthed a novel mode of evolution in which chromosomes retain their content but shuffle the order and orientation of genes. We propose to call this phenomenon mesosynteny. What is the origin and mechanism of mesosynteny? The phenomenon is observed only in the Pezizomycotina and especially in the Dothideomycetes. The Dothideomycetes sequenced to date have several (ten or more) relatively small chromosomes, hinting at the ubiquity of supernumerary chromosomes within this taxon. The Pezizomycotina exhibit repeatinduced point mutation and higher frequencies of lateral gene transfer compared to other fungi [15,51]. Are these phenomena causally related?

The mechanism for mesosynteny may occur through a high frequency of inversions during meiosis. Whether the Dothideomycetes have a higher propensity for inversions is not known but should be the subject of further investigation. Alternatively, lateral gene transfer may be the driving force behind mesosynteny. The mechanism of lateral gene transfer is not well understood, but recent evidence suggests that the sequence transferred can be very large, even up to the size of entire chromosomes $[49,52]$. Fungi are capable of fusing with other fungal species through either conidial or hyphal anastomosis tubes [53]. Fusion can lead to exchange of nuclei and the transient formation of heterkaryotic strains. If the transferred DNA carried a gene that was beneficial to the recipient species, the chromosome (or a large section) carrying this gene may be retained whilst other 
donated chromosomes would be lost. As mesosynteny tends to retain genes on the same chromosomes, a recipient species may be able to accept a substitute chromosome from a reasonably closely related species without major disruption of phenotype. Recombination between the new and old chromosome would shuffle the order and orientation of genes, with remnant duplicated genes being removed in further cycles of repeat-induced point mutation. Recombinants with a complete core gene content plus any advantageous laterally transferred genes would then be selected, resulting in the mesosyntenic pattern of chromosomal conservation we see today. Mesosynteny may, therefore, be an adaptive mechanism that both allowed and resulted from lateral acquisition of large chromosomal sections.

\section{Materials and methods} Whole-genome comparisons

The synteny classification method is outlined in Figure 3. Genome sequence assemblies of the species listed in Figure 1 were obtained from the sources described in Additional file 1. Phylogenetic data (Figure 1; Table 1) were inferred from previous publications $[1,28,54,55]$. Individual sequences (contigs, scaffolds or chromosomes) less than $500 \mathrm{kbp}$ in length were discarded from the analysis. Whole-genome comparisons were performed using promer (MUMmer 3.0, [37]) with the '-mum' parameter. Promer outputs were filtered for repetitive matches using the program 'delta-filter' (MUMmer 3.0) with the '-g' parameter. Genome dot plots were generated using 'mummerplot' (MUMmer 3.0) and coordinates of promer matches were derived from filtered promer outputs using the 'show-coords' program (MUMmer 3.0).

\section{Determination of significant sequence conservation}

For the purposes of this study, only synteny observable at a whole-genome level was considered. For a given pair of genomes (genome A and genome B), all combinations of their sequence (contigs, scaffolds or chromosomes) pairs (one sequence from genome A (sequence A) and one from genome B (sequence B)) were tested for significant conservation. Lengths of conserved regions in sequences A and B were derived from MUMmer outputs. The probability of synteny $\left(\mathrm{P}_{\text {syn }}\right)$ for sequence pairs was calculated via a one-tailed cumulative binomial test:

$$
\mathrm{p}_{\text {syn }}=F(x, p, n)=\sum_{i=0}^{x}\left(\begin{array}{l}
n \\
i
\end{array}\right)(p)^{i}(1-p)^{n-1}
$$

where $\mathrm{x}=$ (Length conserved in sequence $\mathrm{A} \times$ Length conserved in sequence $B$ )/(Length of sequence $A \times$ Length of sequence B); $n=100 ; \mathrm{p}=$ (Total length conserved in Genome A $\times$ Total length conserved in Genome B)/(Total length genome $\mathrm{A} \times$ Total length genome B). $\mathrm{P}_{\text {syn }}$ was required to be $\geq 0.99$ to indicate significant amounts of sequence conservation between a sequence pair.

\section{Analysis of syntenic regions between conserved sequences}

The lengths of syntenic regions were analyzed for significantly conserved sequence pairs. Extended co-linearity of sequence matches visible as uninterrupted diagonal lines on a dot plot was used as an indicator of macrosynteny (Additional file 1). Dot plots between sequence pairs were considered as individual scatter plots. Promer matches between a pair of sequences were converted into a series of points on the scatter plot, with a point added every $1 \mathrm{~kb}$ along each match. $R^{2}$ values were calculated along the axis of sequence $\mathrm{A}$ in $20-\mathrm{kb}$ windows (incrementing along by $2 \mathrm{~kb}$ ). A window was considered to be co-linear if it contained a minimum of 15 data points with an $\mathrm{R}^{2} \geq 0.9$ The end coordinates of co-linear windows were subsequently modified to exclude the coordinate range of overlapping non-co-linear windows. The data points of co-linear windows within $50 \mathrm{~kb}$ of one another were combined (including intermediate data points if not overlapping) and were merged into larger co-linear windows if (Slope of window 1/Slope of window 2) $>0.8$ and $<1.2$. The start and end points of co-linear windows with a length of $\geq 5 \mathrm{~kb}$ were used as the coordinates of 'syntenic regions'. The same process was repeated along the axis of sequence $B$.

\section{Classification of synteny type}

Whole-genome synteny was identified by the 'significant pair ratio' statistic, which is an indicator of the proportion of conserved sequences relative to the expected number of conserved sequences. The significant pair ratio was determined by:

$$
\text { significant pair ratio }=\frac{N_{s c p}}{\sqrt{S_{a} \times S_{b}}}
$$

where $\mathrm{N}_{\mathrm{scp}}$ is the number of significantly conserved pairs between genomes $\mathrm{A}$ and $\mathrm{B} ; \mathrm{S}_{\mathrm{a}}$ is the number of sequences in genome $A \geq 500 \mathrm{~kb}$; and $S_{b}$ is the number of sequences in genome $B \geq 500 \mathrm{~kb}$.

Whole-genome synteny was identified when the significant pair ratio was $\geq 0.25$. Genome pairs failing this criterion were classified as 'non-syntenic'. Genome pairs passing the test for whole-genome synteny were subcategorized as either macrosyntenic or mesosyntenic, defined by an average length of syntenic regions (combined between both compared genomes) of greater than or less than $20 \mathrm{~kb}$, respectively. Synteny type was further 
categorized into 'degraded' or 'non-degraded' based on the statistic 'pair exclusivity'. For a given sequence pair, consisting of sequence $\mathrm{A}$ of genome $\mathrm{A}$ and sequence $\mathrm{B}$ of genome B, the 'pair exclusivity' was calculated by:

$$
\text { Pair exclusivity }=\frac{C_{a b}}{C_{A b}+C_{a B}-C_{a b}}
$$

where $C_{a b}$ is the total length of conserved matches between sequences $A$ and $B ; C_{A b}$ is the total length of conserved matches for sequence $\mathrm{A}$ and all sequences of genome $B$; and $C_{a B}$ is the total length of conserved matches for sequence $\mathrm{B}$ and all sequences of genome $\mathrm{A}$.

Synteny was classified as 'degraded' if the maximum value of all pair exclusivities was less than 0.75 .

\section{Additional material}

Additional file 1: Supplementary Figure S1. The origins of the different types of syntenic relationships. Immediately after a speciation event, equivalent chromosomes in two daughter species retain the gene content, order and orientation of the parent species. (a) Diagrammatic representation of a chromosome with sequential elements $\mathrm{A}$ to $\mathrm{Z}$. (b) A dot plot comparing the chromosomes in (a), with letters substituted for dots. The unbroken series of letters on the diagonal indicates macrosynteny. (c, d) Loss of sequences from each chromosome (c) will degrade the diagonal co-linearity when visualized as a dot plot (d).

Additional file 2: Supplementary Figure S2. (a, b) Correspondence between promer-derived dot plots (a) and blastp-derived protein comparisons of annotated genes (b) between Phaeosphaeria nodorum and Leptosphaeria maculans. Sequence pairs ('boxes') in (a) containing non-random distributions of 'dots' correspond to those in (b), indicating that the back-translated genome matches in (a) correspond to regions of conserved gene content.

Additional file 3: Supplementary File 1. Predictions of synteny between all species involved in this study in an Excel file.

Additional file 4: Supplementary Figure S3. Presence of both macrosyntenic and mesosyntenic conservation patterns between the genomes of Fusarium oxysporum and Nectria haematococca. Core chromosomes (indicated by black bars along the axes) are macrosyntenic between the two species. Dispensable chromosomes (red bars along the axes) are either non-syntenic ( $N$. haematococca chromosomes 15 to 17) or mesosyntenic (N. haematococca chromosomes 7 and 11 to $14, F$. oxysporum chromosome 14). The majority of chromosomes 3 and 6 of $F$. oxysporum had no similarity to the chromosomes of $N$. haematococca except for regions near their telomeres.

Additional file 5: Supplementary Figure S4. Degradation of wholegenome synteny in the classes Saccharomycetes and

Schizosaccharomyces. Whole-genome dot plots have been limited to scaffolds or chromosomes greater than $500 \mathrm{~kb}$. Species of the Saccharomyces and Schizosaccharomyces do not exhibit whole-genome conservation with each other. Certain species within each class exhibit macrosynteny whereas others exhibit no synteny.

Additional file 6: Supplementary Figure S5. Degradation of wholegenome synteny between a member of the class Agaricales and related orders. Whole-genome dot plots have been limited to scaffolds or chromosomes greater than $500 \mathrm{~kb}$. Species in the Agaricales exhibited macrosynteny with each other. However, the Agaricales exhibited no synteny with the closest related classes represented in this study, the Exobasidiomycetes and Pucciniomycetes.

Additional file 7: Supplementary Figure S6. Evidence of degraded mesosynteny between the genomes of two homothallic Sordariomycete species, Fusarium graminearum (order Hypocreales) and Chaetomium globosum (order Sordariales). These two species are estimated to have diverged approximately 225 Mya. Sequence matches (dots) are arranged in blocked clusters typical of mesosynteny. Chromosomes and scaffolds do not share a one-to-one relationship, with multiple mesosyntenic clusters appearing in the same row or column.

\section{Abbreviations}

CDC: conditionally dispensable chromosome; Mya: million years ago.

\section{Author details}

${ }^{1}$ CSIRO Plant Industry, Centre for Environment and Life Sciences, Private Bag 5, Perth, 6193, Australia. 'Faculty of Health Sciences, Murdoch University, Perth, 6150, Australia. ${ }^{3}$ INRA-Bioger, Avenue Lucien Brétignières, BP 01, Thiverval-Grignon, 78850, France. ${ }^{4}$ School of Botany, The University of Melbourne, Melbourne, 3010, Australia. ${ }^{5}$ Wageningen UR, Plant Research International, Department of Biointeractions and Plant Health, PO Box 69, Wageningen, $6700 \mathrm{AB}$, The Netherlands. ${ }^{6}$ USDA-ARS, Crop Production and Pest Control Research Unit, Purdue University, 915 West State Street, West Lafayette, IN 47907-2054, USA. ${ }^{7}$ Australian Centre for Necrotrophic Fungal Pathogens, Curtin University, Perth, 6845, Australia.

\section{Authors' contributions}

RPO and JKH conceived and designed the study. JKH developed algorithms and performed mesosynteny analyses. JKH and RPO wrote the manuscript. TR, BJH, GHJK and SBG contributed data. JKH, RPO, TR, BJH, GHJK and SBG edited the manuscript. All authors read and approved the final manuscript.

Received: 20 February 2011 Revised: 27 April 2011

Accepted: 24 May 2011 Published: 24 May 2011

\section{References}

1. Schoch CL, Sung GH, Lopez-Giraldez F, Townsend JP, Miadlikowska J, Hofstetter V, Robbertse B, Matheny PB, Kauff F, Wang Z, Gueidan C, Andrie RM, Trippe K, Ciufetti LM, Wynns A, Fraker E, Hodkinson BP, Bonito G, Groenewald JZ, Arzanlou M, de Hoog GS, Crous PW, Hewitt D, Pfister DH, Peterson K, Gryzenhout M, Wingfield MJ, Aptroot A, Suh SO, Blackwell $M$, et al: The Ascomycota tree of life: a phylum-wide phylogeny clarifies the origin and evolution of fundamental reproductive and ecological traits. Syst Biol 2009, 58:224-239.

2. Sims GE, Jun SR, Wu GA, Kim SH: Alignment-free genome comparison with feature frequency profiles (FFP) and optimal resolutions. Proc Natl Acad Sci USA 2009, 106:2677-2682.

3. McLysaght A, Enright AJ, Skrabanek L, Wolfe KH: Estimation of synteny conservation and genome compaction between pufferfish (Fugu) and human. Yeast 2000, 17:22-36.

4. Pennacchio LA: Insights from human/mouse genome comparisons. Mamm Genome 2003, 14:429-436.

5. Kohn M, Kehrer-Sawatzki H, Vogel W, Graves JA, Hameister H: Wide genome comparisons reveal the origins of the human $\mathrm{X}$ chromosome. Trends Genet 2004, 20:598-603.

6. Cannon SB, Sterck L, Rombauts S, Sato S, Cheung F, Gouzy J, Wang X, Mudge J, Vasdewani J, Schiex T, Spannagl M, Monaghan E, Nicholson C, Humphray SJ, Schoof H, Mayer KF, Rogers J, Quetier F, Oldroyd GE, Debelle F, Cook DR, Retzel EF, Roe BA, Town CD, Tabata S, Van de Peer Y, Young ND: Legume genome evolution viewed through the Medicago truncatula and Lotus japonicus genomes. Proc Natl Acad Sci USA 2006, 103:14959-14964.

7. Phan HT, Ellwood SR, Hane JK, Ford R, Materne M, Oliver RP: Extensive macrosynteny between Medicago truncatula and Lens culinaris ssp. culinaris. Theor Appl Genet 2007, 114:549-558.

8. Shultz JL, Ray JD, Lightfoot DA: A sequence based synteny map between soybean and Arabidopsis thaliana. BMC Genomics 2007, 8:8.

9. Parkin AP, Lydiate DJ, Trick M: Assessing the level of collinearity between Arabidopsis thaliana and Brassica napus for A. thaliana chromosome 5. Genome 2002, 45:356-366.

10. Ma B: Synteny between Brachypodium distachyon and Hordeum vulgare as revealed by FISH. Chromosome Res 2010, 18:841-850.

11. Zhang Y, Schoch CL, Fournier J, Crous PW, de Gruyter J, Woudenberg JH, Hirayama K, Tanaka K, Pointing SB, Spatafora JW, Hyde KD: Multi-locus 
phylogeny of Pleosporales: a taxonomic, ecological and evolutionary reevaluation. Stud Mycol 2009, 64:85-102S5.

12. Marande W, López-García P, Moreira D: Eukaryotic diversity and phylogeny using small- and large-subunit ribosomal RNA genes from environmental samples. Environ Microbiol 2009, 11:3179-3188.

13. Wang $H$, Guo S, Huang M, Thorsten LH, Wei J: Ascomycota has a faster evolutionary rate and higher species diversity than Basidiomycota. Sci China 2010, 53:1163-1169.

14. Oliver RP, Solomon PS: Recent fungal diseases of crop plants: is lateral gene transfer a common theme? Mol Plant Microbe Interact 2008, 21:287-293.

15. Marcet-Houben M, Gabaldon T: Acquisition of prokaryotic genes by fungal genomes. Trends Genet 2010, 26:5-8.

16. Friesen TL, Stukenbrock EH, Liu Z, Meinhardt S, Ling H, Faris JD, Rasmussen JB, Solomon PS, McDonald BA, Oliver RP: Emergence of a new disease as a result of interspecific virulence gene transfer. Nat Genet 2006, 38:953-956.

17. Chibana H, Oka N, Nakayama H, Aoyama T, Magee BB, Magee PT, Mikami Y: Sequence finishing and gene mapping for Candida albicans chromosome 7 and syntenic analysis against the Saccharomyces cerevisiae genome. Genetics 2005, 170:1525-1537.

18. Borkovich KA, Alex LA, Yarden O, Freitag M, Turner GE, Read ND, Seiler $S$, Bell-Pedersen D, Paietta J, Plesofsky N, Plamann M, Goodrich-Tanrikulu M, Schulte U, Mannhaupt G, Nargang FE, Radford A, Selitrennikoff C, Galagan JE, Dunlap JC, Loros JJ, Catcheside D, Inoue H, Aramayo R, Polymenis M, Selker EU, Sachs MS, Marzluf GA, Paulsen I, Davis R, Ebbole DJ, et al: Lessons from the genome sequence of Neurospora crassa: Tracing the path from genomic blueprint to multicellular organism. Microbiol Mol Biol Rev 2004, 68:1-108.

19. Dean RA, Talbot NJ, Ebbole DJ, Farman ML, Mitchell TK, Orbach MJ, Thon M, Kulkarni R, Xu JR, Pan H, Read ND, Lee YH, Carbone I, Brown D, Oh YY, Donofrio N, Jeong JS, Soanes DM, Djonovic S, Kolomiets E, Rehmeyer C, Li W, Harding M, Kim S, Lebrun MH, Bohnert H, Coughlan S, Butler J, Calvo S, Ma LJ, et al: The genome sequence of the rice blast fungus Magnaporthe grisea. Nature 2005, 434:980-986.

20. Espagne E, Lespinet O, Malagnac F, Da Silva C, Jaillon O, Porcel BM, Couloux A, Aury JM, Segurens B, Poulain J, Anthouard V, Grossetete S, Khalili H, Coppin E, Dequard-Chablat M, Picard M, Contamine V, Arnaise S, Bourdais A, Berteaux-Lecellier V, Gautheret D, de Vries RP, Battaglia E, Coutinho PM, Danchin EG, Henrissat B, Khoury RE, Sainsard-Chanet A, Boivin A, Pinan-Lucarre B, et al: The genome sequence of the model ascomycete fungus Podospora anserina. Genome Biol 2008, 9:R77.

21. Hane JK, Lowe RG, Solomon PS, Tan KC, Schoch CL, Spatafora JW, Crous PW, Kodira C, Birren BW, Galagan JE, Torriani SF, McDonald BA, Oliver RP: Dothideomycete plant interactions illuminated by genome sequencing and EST analysis of the wheat pathogen Stagonospora nodorum. Plant Cell 2007, 19:3347-3368.

22. Nierman WC, Pain A, Anderson MJ, Wortman JR, Kim HS, Arroyo J, Berriman M, Abe K, Archer DB, Bermejo C, Bennett J, Bowyer P, Chen D, Collins M, Coulsen R, Davies R, Dyer PS, Farman M, Fedorova N, Fedorova N, Feldblyum TV, Fischer R, Fosker N, Fraser A, Garcia JL, Garcia MJ, Goble A, Goldman GH, Gomi K, Griffith-Jones S, et al: Genomic sequence of the pathogenic and allergenic filamentous fungus Aspergillus fumigatus. Nature 2005, 438:1151-1156.

23. Machida M, Terabayashi Y, Sano M, Yamane N, Tamano K, Payne GA, Yu J, Cleveland TE, Nierman WC: Genomics of industrial Aspergilli and comparison with toxigenic relatives. Food Addit Contam Part A Chem Anal Control Expo Risk Assess 2008, 25:1147-1151.

24. Machida M, Asai K, Sano M, Tanaka T, Kumagai T, Terai G, Kusumoto K, Arima T, Akita O, Kashiwagi Y, Abe K, Gomi K, Horiuchi H, Kitamoto K, Kobayashi T, Takeuchi M, Denning DW, Galagan JE, Nierman WC, Yu J, Archer DB, Bennett JW, Bhatnagar D, Cleveland TE, Fedorova ND, Gotoh O, Horikawa H, Hosoyama A, Ichinomiya M, Igarashi R, et al: Genome sequencing and analysis of Aspergillus oryzae. Nature 2005, 438:1157-1161.

25. Pel HJ, de Winde JH, Archer DB, Dyer PS, Hofmann G, Schaap PJ, Turner G, de Vries RP, Albang R, Albermann K, Andersen MR, Bendtsen JD, Benen JA, van den Berg M, Breestraat S, Caddick MX, Contreras R, Cornell M, Coutinho PM, Danchin EG, Debets AJ, Dekker P, van Dijck PW, van Dijk A, Dijkhuizen L, Driessen AJ, d'Enfert C, Geysens S, Goosen C, Groot GS, et al:
Genome sequencing and analysis of the versatile cell factory Aspergillus niger CBS 513.88. Nat Biotechnol 2007, 25:221-231.

26. Maizel JV Jr, Lenk RP: Enhanced graphic matrix analysis of nucleic acid and protein sequences. Proc Natl Acad Sci USA 1981, 78:7665-7669.

27. Solomon PS, Lowe RGT, Tan KC, Waters ODC, Oliver RP: Stagonospora nodorum: cause of stagonospora nodorum blotch of wheat. Mol Plant Pathol 2006, 7:147-156.

28. Schoch CL, Crous PW, Groenewald JZ, Boehm EW, Burgess TI, de Gruyter J, de Hoog GS, Dixon L, Grube M, Gueidan C, Harada Y, Hatakeyama S, Hirayama K, Hosoya T, Huhndorf SM, Hyde KD, Jones EB, Kohlmeyer J, Kruys A, Li YM, Lucking R, Lumbsch HT, Marvanova L, Mbatchou JS, McVay AH, Miller AN, Mugambi GK, Muggia L, Nelsen MP, Nelson P, et al: A class-wide phylogenetic assessment of Dothideomycetes. Stud Mycol 2009, 64:1-15S10.

29. Cooley RN, Caten CE: Variation in electrophoretic karyotype between strains of Septoria nodorum. Mol Gen Genet 1991, 228:17-23.

30. Bringans S, Hane JK, Casey T, Tan KC, Lipscombe R, Solomon PS, Oliver RP: Deep proteogenomics; high throughput gene validation by multidimensional liquid chromatography and mass spectrometry of proteins from the fungal wheat pathogen Stagonospora nodorum. BMC Bioinformatics 2009, 10:301.

31. Casey T, Solomon PS, Bringans S, Tan KC, Oliver RP, Lipscombe R: Quantitative proteomic analysis of G-protein signalling in Stagonospora nodorum using isobaric tags for relative and absolute quantification. Proteomics 2010, 10:38-47.

32. Tan K-C, Heazlewood JL, Millar AH, Oliver RP, Solomon PS: Proteomic identification of extracellular proteins regulated by the Gna1 Ga subunit in Stagonospora nodorum. Mycol Res 2009, 113:523-531.

33. Oliver RP, Solomon PS: New developments in pathogenicity and virulence of necrotrophs. Curr Opin Plant Biol 2010, 13:415-419.

34. Liu Z, Faris JD, Oliver RP, Tan KC, Solomon PS, MCDonald MC, MCDonald BA Nunez A, Lu S, Rasmussen JB, Friesen TL: SnTox3 acts in effector triggered susceptibility to induce disease on wheat carrying the Snn3 gene. PLOS Path 2009, 5:e1000581.

35. Friesen TL, Faris JD, Solomon PS, Oliver RP: Host-specific toxins: Effectors of necrotrophic pathogenicity. Cell Microbiol 2008, 10:1421-1428.

36. Friesen TL, Zhang Z, Solomon PS, Oliver RP, Faris JD: Characterization of the interaction of a novel Stagonospora nodorum host-selective toxin with a wheat susceptibility gene. Plant Physiol 2008, 146:682-693.

37. Kurtz S, Phillippy A, Delcher AL, Smoot M, Shumway M, Antonescu C, Salzberg SL: Versatile and open software for comparing large genomes. Genome Biol 2004, 5:R12.

38. Rouxel T, Grandaubert J, Hane J, Hoede C, van de Wouw A, Couloux A, Dominguez V, Anthouard V, Bally P, Bourras S, Cozijnsen A, Ciuffetti L, Dimaghani A, Duret L, Fudal I, Goodwin S, Gout L, Glaser N, Kema G, Lapalu N, Lawrence C, May K, Meyer M, Ollivier B, Poulain J, Turgeon G, Tyler BM, Vincent D, Weissenbach J, Amselem J, et al: The compartmentalized genome of Leptosphaeria maculans: diversification of effectors within genomic regions affected by Repeat Induced Point mutations. Nat Commun 2011, 2:art.202.

39. Goodwin SB, Ben M'Barek S, Dhillon B, Wittenberg A, Crane CF, Van der Lee TAJ, Grimwood J, Aerts A, Antoniw J, Bailey A, Bluhm B, Bowler J, Bristow J, Brokstein P, Canto-Canche B, Churchill A, Conde-Ferràez L, Cools H, Coutinho PM, Csukai M, Dehal P, Donzelli B, Foster AJ, HammondKosack K, Hane J, Henrissat B, Kilian A, Koopmann E, Kourmpetis Y, Kuo A, et al: Finished genome of Mycosphaerella graminicola reveals stealth pathogenesis and dispensome structure. PLoS Genetics -D-10-00112R2 2011.

40. Passarge E, Horsthemke B, Farber RA: Incorrect use of the term synteny. Nat Genet 1999, 23:387.

41. Broad Institute. [http://www.broadinstitute.org/].

42. DOE Joint Genome Institute. [http://www.jgi.doe.gov/].

43. S. sclerotiorum Sequencing Project. [http://www.broadinstitute.org/ annotation/genome/sclerotinia_sclerotiorum/Info.html].

44. Giles NH, Geever RF, Asch DK, Avalos J, Case ME: Organization and regulation of the qa (quinic acid) genes in Neurospora crassa and other fungi. J Hered 1991, 82:1-7.

45. Putnam NH, Butts T, Ferrier DEK, Furlong RF, Hellsten U, Kawashima T, Robinson-Rechavi M, Shoguchi E, Terry A, Yu K Jr, Benito-Gutiérrez Ė, Dubchak I, Garcia-Fernàndez J, Gibson-Brown JJ, Grigoriev IV, Horton AC, De 
Jong PJ, Jurka J, Kapitonov W, Kohara Y, Kuroki Y, Lindquist E, Lucas S, Osoegawa K, Pennacchio LA, Salamov AA, Satou Y, Sauka-Spengler T, Schmutz J, Shin-I T, et al: The amphioxus genome and the evolution of the chordate karyotype. Nature 2008, 453:1064-1071.

46. Martin F, Kohler A, Murat C, Balestrini R, Coutinho PM, Jaillon O, Montanini B, Morin E, Noel B, Percudani R, Porcel B, Rubini A, Amicucci A, Amselem J, Anthouard V, Arcioni S, Artiguenave F, Aury JM, Ballario P, Bolchi A, Brenna A, Brun A, Buee M, Cantarel B, Chevalier G, Couloux A, Da Silva C, Denoeud F, Duplessis S, Ghignone S, et al: Perigord black truffle genome uncovers evolutionary origins and mechanisms of symbiosis. Nature 2010, 464:1033-1038.

47. Yun SH, Arie T, Kaneko I, Yoder OC, Turgeon BG: Molecular organization of mating type loci in heterothallic, homothallic, and asexual Gibberella/ Fusarium species. Fungal Genet Biol 2000, 31:7-20.

48. Fisher MC, Hanage WP, De Hoog S, Johnson E, Smith MD, White NJ Vanittanakom N: Low effective dispersal of asexual genotypes in heterogeneous landscapes by the endemic pathogen penicillium marneffei. PLoS Path 2005, 1:0159-0165.

49. Wittenberg AH, van der Lee TA, Ben M'barek S, Ware SB, Goodwin SB, Kilian A, Visser RG, Kema GH, Schouten HJ: Meiosis drives extraordinary genome plasticity in the haploid fungal plant pathogen Mycosphaerella graminicola. PLoS One 2009, 4:e5863.

50. Ma LJ, van der Does HC, Borkovich KA, Coleman JJ, Daboussi MJ, Di Pietro A, Dufresne M, Freitag M, Grabherr M, Henrissat B, Houterman PM, Kang S, Shim WB, Woloshuk C, Xie X, Xu JR, Antoniw J, Baker SE, Bluhm BH, Breakspear A, Brown DW, Butchko RA, Chapman S, Coulson R, Coutinho PM, Danchin EG, Diener A, Gale LR, Gardiner DM, Goff S, et al: Comparative genomics reveals mobile pathogenicity chromosomes in Fusarium. Nature 2010, 464:367-373.

51. Clutterbuck JA: Genomic evidence of repeat-induced point mutation (RIP) in filamentous ascomycetes. Fungal Genet Biol 2011, 48:306-326

52. Akagi Y, Akamatsu H, Otani H, Kodama M: Horizontal chromosome transfer, a mechanism for the evolution and differentiation of a plantpathogenic fungus. Eukaryot Cell 2009, 8:1732-1738.

53. Roca M, Read N, Wheals A: Conidial anastomosis tubes in filamentous fungi. FEMS Micro Letts 2005, 249:191-198.

54. Liu Y, Leigh JW, Brinkmann H, Cushion MT, Rodriguez-Ezpeleta N, Philippe H, Lang BF: Phylogenomic analyses support the monophyly of Taphrinomycotina, including Schizosaccharomyces fission yeasts. Mol Biol Evol 2009, 26:27-34.

55. Shertz CA, Bastidas RJ, Li W, Heitman J, Cardenas ME: Conservation, duplication, and loss of the Tor signaling pathway in the fungal kingdom. BMC Genomics 2010, 11:510.

\section{doi:10.1186/gb-2011-12-5-r45}

Cite this article as: Hane et al:: A novel mode of chromosomal evolution peculiar to filamentous Ascomycete fungi. Genome Biology 2011 12:R45.

\section{Submit your next manuscript to BioMed Central and take full advantage of:}

- Convenient online submission

- Thorough peer review

- No space constraints or color figure charges

- Immediate publication on acceptance

- Inclusion in PubMed, CAS, Scopus and Google Scholar

- Research which is freely available for redistribution 